\title{
SOIL FLOODING TOLERANCE IN LENTIL AT VEGETATIVE STAGE
}

\author{
B. Nessa, M. R. Islam ${ }^{1}$, M. M. Haque ${ }^{1}$ and J. U. Ahmed ${ }^{2}$ \\ Department of Agronomy, Bangabandhu Sheikh Mujibur Rahman Agricultural \\ University, Gazipur-1706, Bangladesh
}

\begin{abstract}
The experiment compared the relative tolerance of some advanced lines and a variety of lentil viz. BD3859, BD3905, BD3867, ILL5087, ILL5133 and BINAmasur1 (variety) to soil flooding. The growth rates of the genotypes considerably reduced when flooding imposed at vegetative stage. However, the genotypes responded differently to flooding onward during recovery period. Leaf and roots showed highly vulnerable to flooding. Flooding promoted extensive leaf senescence and desiccation. Flooding induced damaging of root system was highly striking, despite there existed remarkable recoveries in some genotypes. The adverse effect of flooding was less pronounced on stem than other plant components. However, shoot growth reduction was $76-86 \%$ relative to control. Relative growth rate (RGR) of most plant components showed negative rate during flooding, but it varied from negative to positive during recovery period. Considering total plant biomass, flooding tolerance (FT) indices indicated that BINAmasur1 and BD3859 had comparatively better degree of tolerance to excess water. In contrast, ILL5133 and ILL5087 were susceptible to flooding for having negative FT indices.
\end{abstract}

Key Words : Flooding, Lentil, Tolerance, Vegetative stage

\section{INTRODUCTION}

Lentil (Lens culinaries Medic.) is the second largest pulse produced in Bangladesh after khesari, but stands first in consumer's preference (Afzal et al., 2003; Miah and Rahman, 1998). The crop is grown with an average yield of $752 \mathrm{~kg}$ per hectare and contributes about $33 \%$ to the total pulses production of the country (BBS, 2002). Lentil is high in fibre and protein, but low in fat and free of cholesterol (Podder et al., 1999). In addition, it enriches soil fertility by fixing large quantities of atmospheric nitrogen (Bokhari and Ashraf, 1990). In spite of various benefits of lentil cultivation, its large scale adoption is constrained by low yield potential. Many biotic and abiotic factors are attributed to low yield of the crop. Among the abiotic stresses, excess moisture is considered as major one.

Lentil cultivation is mostly concentrated in the Gangetic floodplain of western part of Bangladesh. The crop is cultivated in the post-rainy winter (Rabi) season. The growth and development of the crop mostly depends on residual soil moisture after the end of

\footnotetext{
1 Department of Agronomy, ${ }^{2}$ Department of Crop Botany, Bangabandhu Sheikh Mujibur Rahman Agricultural University, Gazipur-1706, Bangladesh
} 
monsoon (Miah and Rahman, 1998). However, erratic rain and poor surface drainage during early or later stages of crop growth may result in excess moisture or even transient flooding. As a result, the damage of the crop from flooding or excess soil moisture is not uncommon. Generally, lentil cannot withstand flooding, waterlogging, or soils with high salinity (Heuke, 1999; McVicar and Vandenberg, 2007). The varieties of lentil widely used in Bangladesh are reported susceptible to excess moisture (Afzal et al., 2003). Under such a situation variety(s) tolerant to excess soil moisture might be an option to increase yield and sustainability of growing lentil. Alcalde and Summerfield (1994) studied considerably details on the waterlogging responses of lentil genotypes and found genotypic differences of plant attributes in responses to anoxia. Although there have been many reports emphasized the sensitivity of the crop to excess soil moisture, quantitative information is lacking on the plant traits most sensitive to stress (Summerfield, 1988). Therefore, the study aims at evaluating the flooding induced changes in plant growth of lentil and estimating level of tolerance to soil flooding at vegetative stage.

\section{MATERIALS AND METHODS}

The experiment was carried out in a vinyl house at the Environmental Stress Research Site of Bangabandhu Sheikh Mujibur Rahman Agricultural University (BSMRAU), Gazipur from November 2005 to January 2006. The soil was silt loam and slightly acidic with very low content of nitrogen and medium amount of phosphorus. The mean monthly maximum temperature was in November $\left(29.5^{\circ} \mathrm{C}\right)$ and minimum in December $\left(14.4^{\circ} \mathrm{C}\right)$ during the experimentation. Six lentil genotypes viz. BD3859, BD3905, BD3867, ILL5087, ILL5133 and BINAmasur1 (variety) were used in the experiment. A total 180 seedlings of each genotype were grown in plastic trays of $20 \times 14 \times 5 \mathrm{~cm}$ size on 23 November 2005. The growth medium was soil and well decomposed cowdung in a ratio of $4: 1$. The seedlings were watered regularly to maintain optimum soil moisture condition until the flooding treatment was imposed. Half of the seedlings in each genotype were flooded at 22 days after emergence (DAE) by submerging the base of the seedlings in a water tank of $5 \times 2 \mathrm{~m}$ in size and others were put as non-flooded control. Flooding was continued for 5 days maintaining depth of $1.5 \mathrm{~cm}$ above the soil surface. Thereafter, the seedlings were removed from the tank, excess moisture drained from the tray and the soil was kept optimum soil moisture condition. The optimal soil moisture was provided throughout to the plants retained as non-flooded control. A total six harvests were done for both flooded and non-flooded control at 22, 27, 32, 37, 42 and 52 DAE of which 22-27 DAE was considered as flooding period and 27-52 DAE as recovery period.

At each harvest, data were recorded on plant height, number of leaves and plant components dry weight (DW) i.e. root, stem and leaf. Dry weights were taken after drying the plant parts in an oven at $80^{\circ} \mathrm{C}$ to a constant weight. Total DW for both flooded and control plants was calculated by summing up the dry weights of root, stem and leaf and that of shoot DW by excluding root DW. The relative growth rate (RGR) of plant components biomass and total biomass were calculated as the change in biomass per unit 
time according to Radford (1967). The RGR of each plant attribute under flooded and control conditions were used to calculate flooding tolerance (FT) index according to Chen and Burton (1992) $:$ FT $=$ RGR (flooded) $/$ RGR (non-flooded) $\times 100$. The experiment was arranged in row (six genotypes)-column (two flooding treatments : flooded and nonflooded control) design and replicated fifteen times considering each plant as single replicate. Data recorded on plant height and number of leaves was compared using standard t-test.

\section{RESULTS AND DISCUSSION}

\section{Plant height}

Plant height of flooded plants was not significantly affected at the termination of flooding (27 DAE) and onward 5-day after removal of flooding (Table 1). However, a significant reduction of plant height was observed at 10-day (37 DAE) and onward after termination of flooding in almost all genotypes. In general, height growth was much slower in flooded plants compared to control. The differences in plant height between flooded and control plants widened with the increase of plant age. Plant height reduced only up to $12 \%$ at the end of flooding, but reduction was as much as 34 to $55 \%$ depending on genotypes by the end of the experiment. Height growth reduction against waterlogging has been reported in many plants species viz. mungbean (Ahmed et al., 2002), peanut (Bishnoi and Krishnamoorthy, 1995), winter rape (Zhou and Lin, 1995) and soybean (Scott et al., 1989). However, a partial recovery of plant height has been reported in plant species when plant produced adventitious root (AVRDC, 1993; Reid and Crozier, 1971). In this study, plant height recovery was not remarkable, although variation existed among the genotypes. The genotype ILL-5133 was worst affected showing 28-55\% reduction in plant height, while BINAmasur1 was less affected showing 15-34\% reduction. Among other genotypes, BD3859 was also less affected. Flooding induced genotypic differences in plant height of mungbean have been reported by Islam (2003).

\section{Number of leaves}

Leaves of flooded plants showed pale green in color that eventually turned into yellowish, a conspicuous visual symptom of flooding. Flooding also promoted extensive leaf senescence and desiccation resulting to $18-42 \%$ reduction in number of leaves at 5day after flooding (Table 2). Perhaps, leaf senescence, in spite of few new leaves formation, did not accelerate the growth processes of some genotypes, while others recovered to some extend by the end of the experiment. Recovery of number of leaves generally started at 37 DAE in genotypes BD3859, DB3867 and BINAmasur1, although differences in number of leaves between flooded and control plants broadened showing $76-89 \%$ reduction at the end irrespective of genotypes. It is amusing that the genotype BINAmasur1 showed drastic reduction in number of leaves during flooding compared to control, but this did not appear as constant declining in number of leaves as observed in other genotypes. Matsuura et al. (2005) found that the number of leaves in buckwheat plant was significantly reduced by waterlogging stress to $60 \%$ of the control. The number of leaves per plant during flooding and after termination of flooding also reduced significantly in mungbean plant at vegetative stage (Ahmed et al., 2002). Flood promoting leaf senescence has also been reported in cowpea for which leaf dry matter greatly reduced (Hong et al., 1977). 
Table 1. Genotypic differences in plant height related to flood tolerance in lentil

\begin{tabular}{l|l|c|c|c|c|c|c}
\hline \multirow{2}{*}{ Genotypes } & Flooding & \multicolumn{6}{|c}{ Plant height $(\mathrm{cm})$} \\
\cline { 3 - 7 } & & level & & \multicolumn{6}{|c}{} \\
\cline { 3 - 7 } & & 22 & $27(0)$ & $32(5)$ & $37(10)$ & $42(15)$ & $52(25)$ \\
\cline { 3 - 7 } BD3859 & Flooded & 7.1 & 7.3 & 7.9 & 8.6 & 9.2 & 10.7 \\
& Controlt & 7.5 & 7.9 & 8.4 & $10.8^{* *}$ & $12.8^{*}$ & $16.5^{*}$ \\
BD3905 & Flooded & 6.9 & 7.7 & 8.0 & 8.3 & 8.5 & 8.8 \\
& Control & 6.7 & 7.6 & $9.4^{* *}$ & $11.6^{*}$ & $12.2^{*}$ & $17.6^{*}$ \\
BD3867 & Flooded & 8.3 & 8.6 & 8.0 & 8.3 & 8.4 & 9.5 \\
& Control & 8.2 & 8.9 & 9.1 & $11.0^{*}$ & $12.3^{*}$ & $18.8^{*}$ \\
ILL5087 & Flooded & 6.6 & 6.8 & 7.7 & 7.2 & 7.7 & 8.2 \\
& Control & 6.9 & 7.7 & 8.7 & $9.8^{*}$ & $11.2^{*}$ & $17.9^{*}$ \\
ILL5133 & Flooded & 7.8 & 8.0 & 9.1 & 9.2 & 9.2 & 9.4 \\
& Control & 8.0 & 8.4 & 9.8 & $12.8^{*}$ & $14.7^{*}$ & $20.8^{*}$ \\
BINAmasur1 & Flooded & 7.0 & 7.1 & 6.6 & 6.7 & 7.2 & 8.2 \\
& Control & 6.8 & 7.2 & 7.5 & $7.9^{* *}$ & $10.0^{*}$ & $12.4^{*}$ \\
\hline
\end{tabular}

$*(p<0.01)$ and ${ }^{* *}(p=0.05)$, significantly higher in comparison of flooded and control plants (standard t-test, $\mathrm{n}=15$ ); † Control plants were not flooded, but maintained optimum soil moisture condition throughout

\section{Relative growth rate and flooding tolerance}

Flooding severely reduced the root and leaf masses of the genotypes showing negative RGR of these characters (Table 3). Stem growth was also affected to some extent. Genotypic differences in adverse effect of flooding on RGR of plant components were not remarkable during flooding. However, the genotypes responded differentially during subsequent recovery period. During this period, RGR of root and leaf showed either positive or negative and that of stem was positive indicating both root and leaf were most vulnerable in response to flooding. The recovery of BINAmasur1 and BD3859 was better showing positive RGR of all plant components, while ILL5087 and ILL5133 showed negative RGR of root and leaf. Other two genotypes i.e. BD3905 and BD3867 had positive RGR of root and stem and negative RGR of leaf. Flood tolerance (FT) index calculated as the percent ratio as RGR of flooded plants to RGR of control plants indicating the degree of tolerance of lentil genotypes in response to flooding. FT indices of plant components during flooding were mostly negative. This indicates that plant components were highly sensitive to flooding stress immediately after flooding. However, plants of some genotypes could acclimatize with the flooding situation showing positive FT indices of most plant components. FT indices varied between (-) 87 and 51 in root, 29 and 71 in stem and (-) 27 and 24 in leaf depending on genotypes. The genotype BINAmasur1 was superior having better FT of root, stem and leaf indicating higher degree of tolerance to excess moisture to these characters. This was followed by the genotype BD3859. The genotypes ILL5087 and ILL5133 were worst affected showing negative FT indices of root and leaf. Other two genotypes performed moderately in respect of tolerance index. 
Table 2. Genotypic differences in number of leaves related to flood tolerance in lentil

\begin{tabular}{l|l|c|c|c|c|c|c}
\hline \multirow{2}{*}{ Genotypes } & Flooding & \multicolumn{6}{|c}{ Number of leaves } \\
\cline { 3 - 7 } & & level & Days after emergence (days after removal of flooding in parenthesis) \\
\cline { 3 - 7 } & & 22 & $27(0)$ & $32(5)$ & $37(10)$ & $42(15)$ & $52(25)$ \\
\hline BD3859 & Flooded & 10.9 & 9.2 & 7.9 & 8.1 & 8.4 & 8.4 \\
& Control† & 10.5 & $11.9^{*}$ & $12.7^{*}$ & $18.7^{*}$ & $24.6^{*}$ & $35.6^{*}$ \\
BD3905 & Flooded & 11.6 & 11.2 & 7.0 & 7.8 & 6.6 & 6.3 \\
& Control & 11.9 & $13.7^{*}$ & $19.0^{*}$ & $22.4^{*}$ & $25.0^{*}$ & $36.3^{*}$ \\
BD3867 & Flooded & 12.7 & 11.7 & 5.7 & 6.3 & 7.9 & 7.7 \\
& Control & 12.3 & $14.3^{* *}$ & $16.2^{*}$ & $21.3^{*}$ & $26.0^{*}$ & $32.7^{*}$ \\
ILL5087 & Flooded & 12.7 & 10.1 & 6.3 & 5.8 & 4.7 & 4.0 \\
& Control & 12.2 & $15.5^{*}$ & $20.0^{*}$ & $24.9^{*}$ & $28.0^{*}$ & $36.0^{*}$ \\
ILL5133 & Flooded & 10.1 & 8.9 & 7.7 & 7.3 & 5.9 & 5.4 \\
& Control & 9.2 & $11.6^{*}$ & $12.2^{*}$ & $14.6^{*}$ & $18.1^{*}$ & $28.6^{*}$ \\
BINAmasur1 & Flooded & 13.5 & 12.5 & 7.2 & 9.7 & 10.3 & 11.5 \\
& Control & 13.5 & $21.7^{*}$ & $25.0^{*}$ & $36.9^{*}$ & $45.9^{*}$ & $53.6^{*}$ \\
\hline
\end{tabular}

$*(\mathrm{p}<0.01)$ and $* *(\mathrm{p}=0.05)$, significantly higher in comparison of flooded and control plants (standard t-test, $\mathrm{n}=15$ ); † Control plants were not flooded, but maintained optimum soil moisture condition throughout

Table 3. Relative growth rate (RGR, g/g/day) and flooding tolerance (FT, \%) of root, stem and leaf in lentil genotypes

\begin{tabular}{ll|c|c|c|c|c|c}
\hline \multirow{2}{*}{ Genotypes } & \multirow{2}{*}{ RGR and FT } & \multicolumn{2}{c}{ Flooding period (22-27 DAE) } & \multicolumn{3}{c}{ Recovery period (27-52 DAE) } \\
\cline { 3 - 8 } & & Root & Stem & Leaf & Root & Stem & Leaf \\
\hline BD3859 & RGR flooded & -0.081 & 0.045 & -0.017 & 0.008 & 0.028 & 0.008 \\
& RGR control & 0.058 & 0.045 & 0.025 & 0.036 & 0.076 & 0.077 \\
& Tolerance & -140 & 100 & -68 & 22 & 37 & 10 \\
BD3905 & RGR flooded & -0.058 & -0.027 & -0.008 & 0.006 & 0.025 & -0.011 \\
& RGR control & 0.085 & 0.034 & 0.043 & 0.049 & 0.079 & 0.071 \\
& Tolerance & -68 & -79 & -19 & 12 & 32 & -15 \\
BD3867 & RGR flooded & -0.073 & 0.010 & -0.019 & 0.015 & 0.025 & -0.006 \\
& RGR control & 0.040 & 0.020 & 0.024 & 0.037 & 0.074 & 0.066 \\
& Tolerance & -183 & 50 & -79 & 41 & 34 & -9 \\
& RGR flooded & -0.030 & 0.036 & -0.008 & -0.009 & 0.019 & -0.014 \\
ILL5887 & RGR control & 0.029 & 0.064 & 0.028 & 0.062 & 0.065 & 0.069 \\
& Tolerance & -103 & 56 & -29 & -15 & 29 & -20 \\
& RGR flooded & -0.021 & 0.013 & -0.025 & -0.047 & 0.034 & -0.020 \\
& RGR control & 0.034 & 0.014 & 0.016 & 0.054 & 0.088 & 0.074 \\
& Tolerance & -62 & 93 & -156 & -87 & 39 & -27 \\
BINAmasury 133 1 & RGR flooded & -0.063 & -0.019 & -0.038 & 0.033 & 0.053 & 0.016 \\
& RGR control & 0.126 & 0.031 & 0.066 & 0.065 & 0.075 & 0.068 \\
& Tolerance & -50 & -61 & -58 & 51 & 71 & 24 \\
\hline
\end{tabular}


Table 4. Relative growth rate (RGR, g/g/day) and flooding tolerance (FT, \%) of shoot and total plant in lentil genotype

\begin{tabular}{lll|c|c|c}
\hline \multirow{2}{*}{ Genotypes } & \multirow{2}{*}{ RGR and FT } & \multicolumn{2}{c|}{ Flooding period (22-27 DAE) } & \multicolumn{2}{c}{ Recovery period (27-52 DAE) } \\
\cline { 3 - 6 } & & Shoot & Total plant & Shoot & Total plant \\
\hline BD3859 & RGR flooded & 0.005 & -0.033 & 0.017 & 0.014 \\
& RGR control & 0.032 & 0.046 & 0.077 & 0.059 \\
& Tolerance & 16 & -72 & 22 & 24 \\
BD3905 & RGR flooded & -0.015 & -0.032 & 0.006 & 0.006 \\
& RGR control & 0.04 & 0.062 & 0.075 & 0.063 \\
& Tolerance & -38 & -52 & 8 & 10 \\
BD3867 & RGR flooded & -0.008 & -0.036 & 0.010 & 0.012 \\
& RGR control & 0.023 & 0.031 & 0.069 & 0.056 \\
& Tolerance & -35 & -116 & 14 & 21 \\
& RGR flooded & 0.010 & -0.008 & 0.004 & -0.001 \\
& RGR control & 0.042 & 0.036 & 0.067 & 0.065 \\
& Tolerance & 24 & -22 & 6 & -2 \\
& RGR flooded & -0.010 & -0.015 & 0.011 & -0.008 \\
& RGR control & 0.015 & 0.025 & 0.08 & 0.068 \\
& Tolerance & -67 & -60 & 14 & -12 \\
BINAmas3 & RGR flooded & -0.032 & -0.045 & 0.033 & 0.033 \\
& RGR control & 0.055 & 0.088 & 0.071 & 0.068 \\
& Tolerance & -58 & -51 & 46 & 49 \\
\hline
\end{tabular}

Relative growth rate (RGR) of total plant biomass in all genotypes was negative during flooding (Table 4). This means that plant components were highly affected during flooding and eventually flooded plants supplemented none in the production of total biomass in plants. At the same time RGR of shoot biomass was less affected compared to that of total. However, these two parameters responded differently during recovery period. In this period, RGR of shoot always remained positive value, but total biomass production displayed either positive or negative. This implies that root development rather than shoot played the most vital role in the production of total biomass in plants under flooding situation. It is evident that the RGR of root showed positive or negative values indicating variation in root system development under flooded conditions that reflected in total biomass production of the genotypes. Flood tolerance value during flooding indicates that genotypes were highly responsive to flooding in the production of total biomass immediately after flooding and degree of responsiveness was less pronounced in shoot than total biomass. However, the genotypic differences in FT were highly evident during post-flooding period. In this period, BINAmasur1 showed the highest FT indices of 46 and 49 for shoot and total, respectively and hence this genotype appeared as the superior to others in flooding tolerance. This was followed by the genotype BD3859. The negative FT indices in ILL5133 and ILL5087 for total plant biomass indicate that although the plants of these genotypes had positive growth in stem and eventually in shoot, for more negative RGR of leaf and root, these genotypes failed to 
accelerate their growth processes and hence the genotypes can be designated as highly susceptible to flooding. However, FT indices of the genotypes BD3905 and BD3867 were positive for both shoot and root indicating certain degree of tolerance to flooding.

\section{CONCLUSION}

Lentil can withstand 5-day flooding at vegetative stage, although the growth impaired to a great extent. Flooding greatly affected plant components and thereby accumulated lesser amount of total plant biomass. The genotypic differences in biomass accumulation during recovery were highly evident in the study. Among the tested genotypes, BINAmasur1 had a fair degree of tolerance to soil flooding. However, evaluation of the genotypes under field condition would be necessary for affirmation of flooding tolerance in lentil.

\section{REFERENCES}

Afzal, M. A., Bakr, M. A., Hamid, A., Haque, M. M. and Aktar, M. S. 2003. Lentil in Bangladesh. Lentil Blackgram and Mungbean Development Pilot Project, Pulse Research Station, BRRI, Gazipur-1706, Publ. 24, p. 19.

Ahmed, S., Nawata E. and Sakuratani, T. 2002. Effects of waterlogging at vegetative and reproductive growth stages on photosynthesis, leaf water potential and yield of mungbean. Plant Prod. Sci., 5 : 117-123.

Alcalde, J. A. and Summerfield, R. J. 1994. Effect of waterlogging during the vegetative stage on growth and development of lentil. LENS Newsl., 21(1) : 22-29.

AVRDC (Asian Vegetable Research and Development Center). 1993. Progress Report for 1992, AVRDC, Shanhua, Taiwan, Pub. No. 93-392.

BBS (Bangladesh Bureau of Statistics). 2002. Year Book of Agricultural Statistics of Bangladesh. Statistics Division, Ministry of Planning, Government of Bangladesh.

Bishnoi, N. R. and Krishnamoorthy, H. N. 1995. Effect of waterlogging and gibberellic acid on growth and yield of peanut (Arachis hpogaca L.). Indian J. Plant physiol., 38 : 45-47.

Bokhari, M. H. and Ashraf, M. 1990. Pulse Crops of Pakistan. The Biological Society of Pakistan, Lahore.

Chen, J. W. Y. and Burton, R. S. 1992. Variation in alcohol dehydrogenase activity and flood tolerance in white clover Trifolium Repens. Evolution, $46: 721-734$.

Heuke, L. 1999. Emerging opportunity in agriculture. The Australian New Crop Newsl. Pobl., 11.

Hong, T. D., Minchin, F. R. and Summerfield, R. J. 1977. Recovery of nodulated cowpea plants (Vigna unguicculata L. WALP.) from waterlogging during vegetative growth. Plant Soil, 48 : 661-672.

Islam, M. R. 2003. Eco-physiology of soil flooding tolerance in mungbean. Ph. D. Thesis, Bangabandhu Sheikh Mujibur Rahman Agricultural University, Gazipur, Bangladesh.

Matsuura. A., Inanaga, S., Tetsuka, T. and Murata, K. 2005. Differences in the vegetative growth response to soil flooding between common and tartury buckwheat. Plant Prod. Sci., 8 : 525-532.

McVicar, R. and Vandenberg, A. 2007. Red lentil production. Saskatchewan Agriculture and Food. Website: hptt://www.agr.gov.sk.ac/. 
Miah, A. A. and Rahman, M. M. 1998. Agronomy of Lentil in Bangladesh. In : Lentil in South Asia Proceedings of the seminar on lentil in South Asia, 11-15 March 1991, New Delhi, India pp. 128-138.

Podder, A. K., Islam, M. Z., Rashid, M. H., Chowdhury, S. and Pasha, M. N. U. 1999. Bio-fertilizer and our Agriculture. A bulletin in Bengali, BINA, Mymensingh, Bangladesh.

Radford, P. J. 1967. Growth analysis formulae-their use and abuse. Crop Sci., $7: 171-175$.

Reid, D. M. and Crozier, A. 1971. Effect of waterlogging on the gibberellin content and growth of tomato plants. J. Exp. Bot., 22 : 39-48.

Scott, H. D., DeAngulo, J., Daniels, M. B. and Wood, L. S. 1989. Flood duration effects on soybean growth and yield. Agron. J., $81:$ 631-636.

Summerfield, R. J. 1988. World Crops : Cool Season Food Legumes. Kluwer Academic Publishers, Dordrecht, The Netherlands.

Zhou, W. and Lin, X. 1995. Effects of waterlogging at different growth stages on physiological characteristics and seed yield of winter rape (Brasica napus L.). Field Crops Res., 44 : 103-110. 